\title{
Surgical management of vaginal agenesis using a modified Mc Indoe's technique: VIMS experience
}

\author{
Chandrashekhar Tharihalli ${ }^{1 *}$, Muralikrishna V. ${ }^{2}$, Shiva Kumar H. C. ${ }^{1}$
}

${ }^{1}$ Department of Obstetrics and Gynecology, ${ }^{2}$ Department of Plastic Surgery, VIMS, Ballari, Karnataka, India

Received: 28 July 2017

Accepted: 31 July 2017

\section{*Correspondence:}

Dr. Chandrashekhar Tharihalli,

E-mail: cstobg@gmail.com

Copyright: () the author(s), publisher and licensee Medip Academy. This is an open-access article distributed under the terms of the Creative Commons Attribution Non-Commercial License, which permits unrestricted non-commercial use, distribution, and reproduction in any medium, provided the original work is properly cited.

\begin{abstract}
Background: Mullerian agenesis is a challenge to reconstructive surgeons. In order to create a new vagina that mimic the normal one in size, lining and appearance, multiple techniques have been designed; among these techniques Mc Indoe's vaginoplasty represents the simplest one with good results. Mc Indoe's operation which involves the creation of a space between bladder and rectum, insertion of a mould covered with split-thickness skin graft into that neovaginal space, and use of postoperative vaginal mould for dilation and to avoid stenosis. However, many modifications have been introduced in time in an attempt to increase the success rates. The purpose of vaginal agencies treatment is to create an adequate passage for penetration during sexual intercourse.

Methods: Between Jan 2010 to June 2017, ten patients with vaginal agenesis were admitted to Dept of Obstetrics and Gynaecology, VIMS Ballari for vaginal reconstruction. All cases underwent a modified Mc Indoe's technique, and follow up was done for one year.

Results: All ten cases of vaginal agenesis underwent vaginal reconstruction by modified Mc Indoe's technique. Postoperative vaginal length varied from 5 to $7 \mathrm{~cm}$ in patients who used mould regularly. Successful skin graft take was achieved in 6 cases. one case of perforation of rectum and one case of vaginal stricture was noted.

Conclusions: To optimize sexual comfort, the clinical management of women with vaginal agenesis must be multidisciplinary and individually tailored. Our findings suggest that the modified Mc Indoe's technique is a simple, effective procedure for the treatment of vaginal agenesis, but proper mould usage after surgery remains the cornerstone of the treatment.
\end{abstract}

Keywords: Mc Indoe's vaginoplasty, MRKH syndrome, Mould, Vaginal agenesis

\section{INTRODUCTION}

Mullerian agenesis is a rare but crippling anomaly; its incidence varies from $1: 4000$ to $1: 10000 .{ }^{1}$ The most common etiology is Mayer-Rokitansky-Kuster-Hauser (MRKH) syndrome or Mullerian agenesis which is described as congenital absence of uterus and vagina in an individual with normal female genotype, normal secondary sexual characteristics, and normal ovaries. Vaginal agenesis may also occur as an isolated abnormality. ${ }^{2}$ Vaginal agenesis is most commonly associated with Mayer-Rokitansky-Küster-Hauser (MRKH) syndrome. The vaginal agenesis is often associated with anomalies of the renal (34\%) and the skeletal (12\%) systems. $^{3}$ The Renal anomalies may include unilateral agenesis of the kidney, ectopic kidney(s), horseshoe kidney, and crossed-fused ectopia and skeletal anomalies may include fused vertebrae or other variants.

If it is left untreated, there will be sexual inability and patients may develop severe psycho- logical problems. ${ }^{4}$ The purpose of treatment is not only to create an adequate passage for penetration but also to facilitate satisfactory sexual intercourse. There are several nonsurgical and surgical techniques describe in the literature for treatment 
of vaginal agenesis. ${ }^{5}$ Non-surgical options include vaginal dilatation with dilator, while surgical options include numerous procedures described for creation of neo-vagina with acceptable function, feeling and appearance, they include Serial dilation, Mc Indoe's technique, Vecchietti's technique, Sigmoid or ileal flaps, Gracilis flap, Singapore flap, Expanded vulval flap. ${ }^{6-12}$ Among these options the modified Mc Indoe's technique gained popularity being the simplest operation with very low donor site morbidity. ${ }^{13}$

Long-term changes in neo-vagina created by this technique were area of interest in researches regarding anatomical, histological, chemical, bacteriological and sensory condition. ${ }^{14}$ In this study, we evaluated functional and anatomical result of the patient subjected to this technique.

Objective was to study the result of modified Mc Indoe's technique of vaginal reconstruction with respect to vaginal length and complications in patient with vaginal agenesis

\section{METHODS}

This study was conducted in Dept of OBG, VIMS, Ballari, between January 2010 to June 2017. Ten cases with vaginal agenesis were admitted for vaginal reconstruction during that period. Detailed clinical history, physical examination, ultrasonography and routine investigations were done in all cases. All ten cases underwent vaginal reconstruction by the modified Mc Indoe's technique.

Our team included Gynaecologists and Plastic Surgeon and Anaesthesiologists from our institute. All preoperative investigations and pre-operative preparations were done according to the protocol. All patients were operated under spinal anaesthesia in the lithotomy position with urinary catheterization. Before starting the surgery, prophylactic IV antibiotic was administered. Blind pouch in the place of vagina was dissected gently by blunt and occasional sharp dissection, and advanced between the urethra and bladder in front and rectum behind. The desirable length of neo vagina was created by gentle and meticulous dissection. Now a Humby's knife was used to harvest a split-thickness skin graft from the inner aspect of mid-thigh region. A soft sponge mould of approximately $8 \mathrm{~cm}$ was prepared by using a sterile foam and covering it with double condom with an infant feeding tube kept under the centre if the mould and inner condom was tied at the distal end of the mould. The graft was perforated in multiple places with a scalpel and sewn with absorbable sutures over a smooth-surfaced sponge mould. Now a negative pressure is created in the mould by using 50cc syringe, which was then inserted into the preformed neo-vaginal cavity. The mould was kept in place by suturing labial folds over the mould by interrupted non-absorbable sutures and applying tight dressing. The mould was removed on seventh day and the newly created vagina was irrigated with diluted povidineiodine solution and normal saline, consecutively and mould was kept in place for another seven days. All patients were discharged on fourteenth day after educating them regarding the use of mould continuously for first three months. During this period, she was asked to remove the mould for only short periods of time for vaginal irrigation. After the first three months, the patient was allowed to engage in sexual intercourse in married women. At the follow up visit examination was done to look for the split skin graft take and depth of the vagina and any other complications noted.

\section{RESULTS}

Between Jan 2010 to June 2017, ten patients with vaginal agenesis were admitted to Department of Obstetrics and Gynaecology, VIMS Ballari for vaginal reconstruction, and all underwent vaginal reconstruction by modified $\mathrm{Mc}$ Indoe's technique as described above.

Table 1: Age distribution of patients.

\begin{tabular}{|l|l|}
\hline Age in years & No. of cases $(n=10)$ \\
\hline $15-19$ & 5 \\
\hline $20-24$ & 3 \\
\hline $25-29$ & 1 \\
\hline $30-34$ & 1 \\
\hline
\end{tabular}

The age group of the patients varied from 16 to 32 years (mean age 23 years).

Table 2: Intra-op and post-operative complications.

\begin{tabular}{|ll|}
\hline Complications & No. of cases \\
\hline Perferation of rectum & 1 \\
\hline Vaginal stricture & 1 \\
\hline Lack of skin graft take & 4 \\
\hline
\end{tabular}

In one patient perforation of the rectum occurred accidentally during deep dissection. The defect was managed immediately by suturing the defect and a temporary colostomy was performed and managed accordingly. Four patients had partial failure of skin graft take which were managed by excision of slough and trimming of the graft followed by thorough irrigation with povidine-iodine solution and normal saline. During the follow up one case of vaginal stricture was noted which was managed by serial dilation of vagina. Successful skin graft take was achieved in six cases.

Table 3: Post-operative follow up.

\begin{tabular}{|ll|}
\hline Post-operative follow up & $\begin{array}{l}\text { No. of } \\
\text { cases }\end{array}$ \\
\hline Regular follow up (monthly) for one year & 8 cases \\
\hline Lost for follow up after three months & 2 cases \\
\hline
\end{tabular}

The follow up period was for one year. All patients were asked to come for regular follow up every month. Post- 
operative vaginal length varied from 5 to $7 \mathrm{~cm}$ (mean vaginal length $6 \mathrm{~cm}$ ) in patients who used mould regularly. Two cases used mould irregularly and lost for follow up.

Table 4: Marital status of the patients.

\begin{tabular}{|ll|}
\hline Marital status & No. of cases \\
\hline Married & 2 cases \\
\hline Un married & 8 cases \\
\hline
\end{tabular}

Two out of ten cases were married and both were engaged in sexual intercourse after three months of using mould.

\section{DISCUSSION}

Vaginal agenesis has to be considered when a teenage girl presents with primary amenorrhoea, inability to accomplish sexual intercourse or with periodic abdominal pain. ${ }^{15}$ Creation of new vagina with acceptable and durable size, soft and moist lining as well as aesthetically looking shape with low morbidity is the target of all reconstructive surgeons in management of Mullerian agenesis.

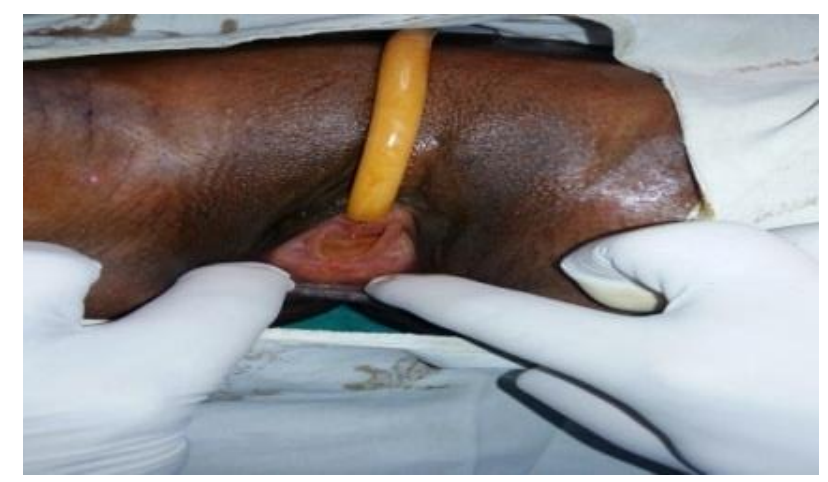

Figure 1: Blind pouch in place of vagina.

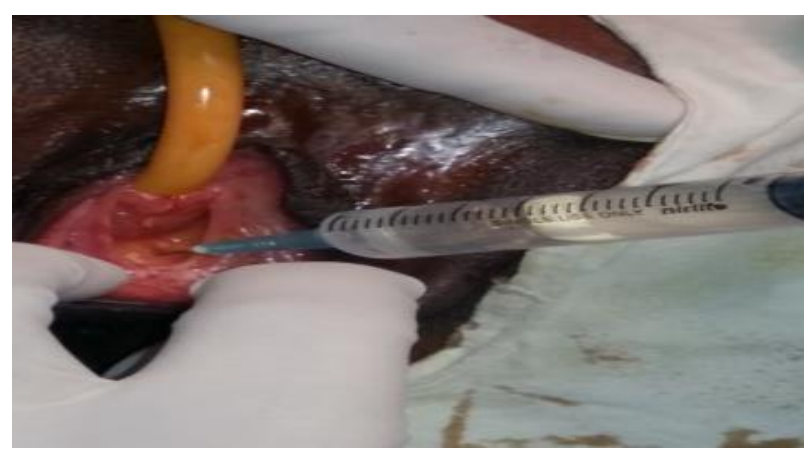

Figure 2: Lignocaine (2\%) infiltration.

For this target, multiple techniques are described ranging from simple skin graft lining for surgically created pouch, to more complex procedure that requires laparotomy and intestinal resection, or harvesting flaps with technical difficulties and lengthy operations.

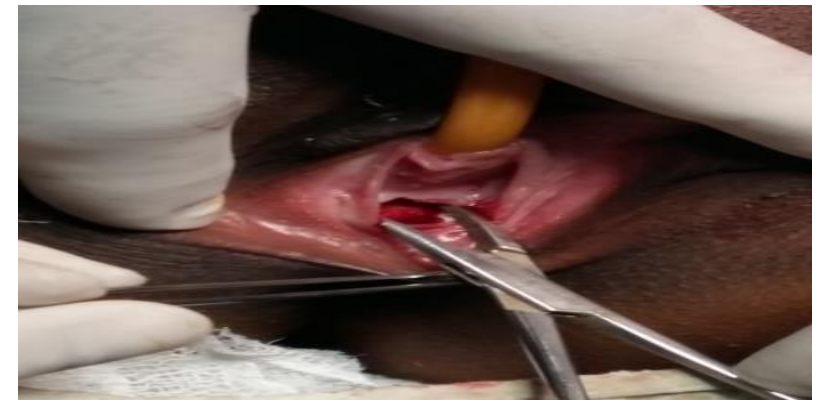

Figure 3: Creation of neo-vagina by sharp dissection.

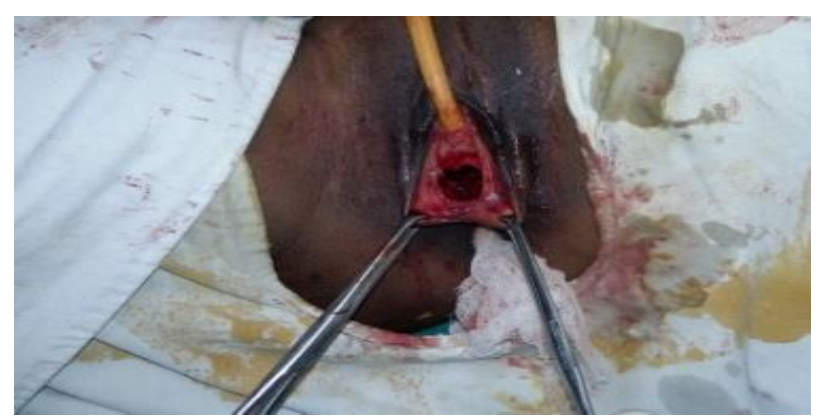

Figure 4: Surgically created neo-vagina.

Out of these techniques, modified Mc Indoe's vaginoplasty so far represents the simplest one with least morbidity, and is the procedure of choice. ${ }^{16}$ This low morbidity is also supported by our result where our patient reported no complication that needed surgical intervention or a complication that has long term sequel.

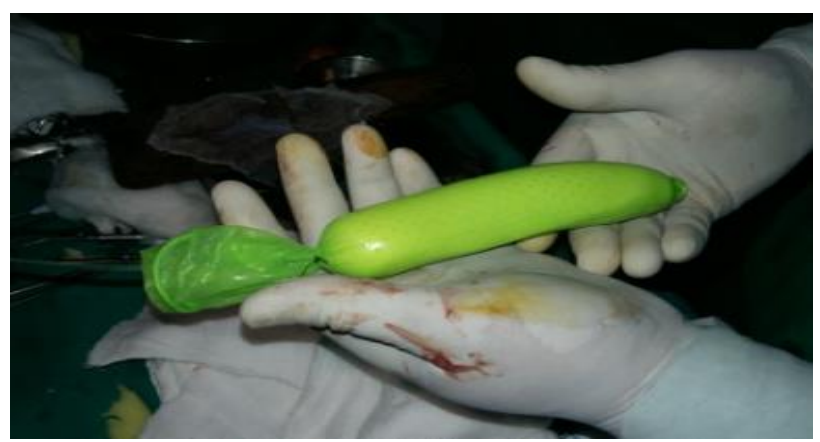

Figure 5: Mould prepared with foam and condom.

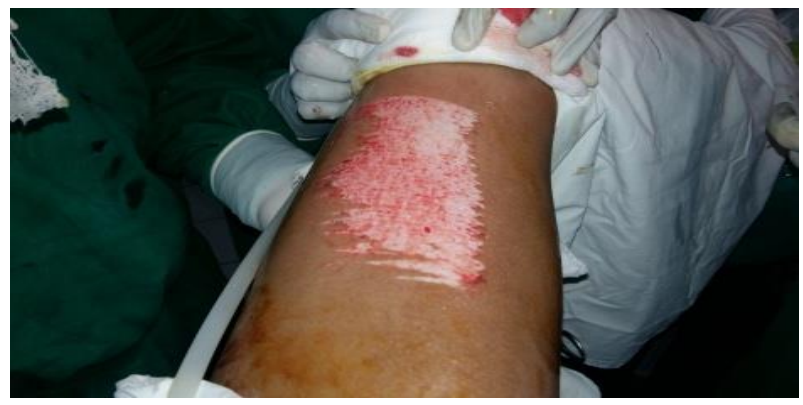

Figure 6: Split thickness skin graft from mid-thigh. 
Mc Indoe's technique not only has minimum complication, but also it can create a neo-vagina that anatomically and functionally looks like the normal one. Regarding anatomical aspect the average size of the vagina that obtained in our study was $6 \mathrm{~cm}$ in length and 2 to $3 \mathrm{~cm}$ diameter, which is approximately the same as it was in other studies, using the same technique, and in this case the dimension of new vagina was approximately similar to that of normal vagina. ${ }^{17}$ This similarity of neovagina to the normal one extended to include the epithelial lining. ${ }^{18}$

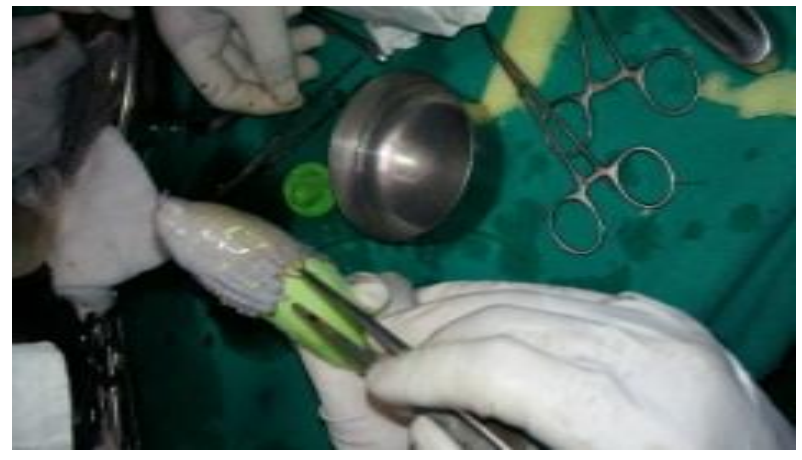

Figure 7: Mould mounted with skin graft-ready for use.

Although most of studies reported a high success rate of Mc Indoe's procedure to restore normal sexual function which varied from $75 \%$ in some series up to $100 \%$ in other studies yet none of them used a specific surveying scale to accurately assess the whole sexual satisfaction. ${ }^{19,20}$ Instead of that, most of these studies relied only on the presence of lubrication and orgasm or absence of pain as an indicator of sexual function. ${ }^{21}$

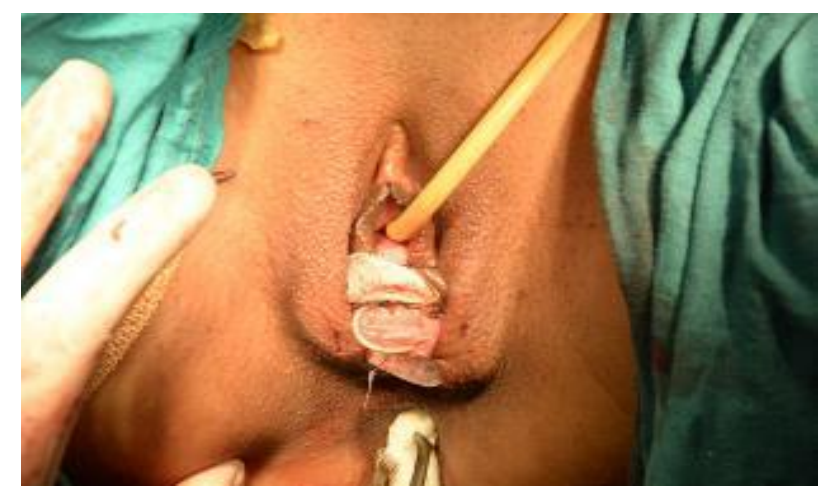

Figure 8: Vaginal mould in place with vulval stitches.

\section{CONCLUSION}

To optimize sexual comfort, the clinical management of women with vaginal agenesis must be multidisciplinary and individually tailored. Present findings suggest that the modified Mc Indoe's technique is a simple, effective procedure for the treatment of vaginal agenesis, but proper mould usage after surgery remains the cornerstone of the treatment.
Funding: No funding sources

Conflict of interest: None declared

Ethical approval: The study was approved by the Institutional Ethics Committee

\section{REFERENCES}

1. Sadove RC and Horton CE. Utilizing full-thickness skin grafts for vaginal reconstruction. Clin Plast Surg. 1988;15:443-8.

2. Practice Committee of the American Society for Reproductive Medicine, Current evaluation of amenorrhea. Fertil Steril. 2006;86(5):148-55.

3. ACOG committee opinion. Nonsurgical diagnosis and management of vaginal agenesis. Int $\mathrm{J}$ Gynecol Obstet. 2002;79(2):167-70.

4. Dixon D, Wali F, Hail S, Welch R, Davis G. Treatment of Vaginal Aplasia among Afghan Women with the McIndoe's Vaginoplasty. Female Pelvic Med Reconst Surg. 2010;16(3):179-87.

5. Bastu E, Akhan SE, Mutlu MF, Nehir A, Yumru H, Hocaoglu E et al. Treatment of vaginal agenesis using a modified Mc Indoe's Technique-long tern follow up of 23 patients and literature review. Can J Plast Surg. 2012;20(4):241-4.

6. Karim RB, Hage JJ, Dekker JJM, Schoot CMH. Evolution of the methods of neo-vaginoplasty for vaginal aplasia. Eur J Obstet, Gynecol Reprod Biol. 1995;58:19-27.

7. Makinoda S, Nishiya M, Sogame M, Mikuni M, Kojo T, Fujino $\mathrm{T}$ et al. Non-grafting method of vaginal construction for patients of vaginal agenesis without functioning uterus (Mayer-RokitanskyKuster syndrome). Int Surg. 1996;81:385-9.

8. Fedele L, Bianchi S, Tozzi L. A new laparoscopic procedure for creation of a neovagina in MayerRokitansky-Kuster-Hauser syndrome. Fertil Steril. 1996;66(5):854-8.

9. Wesley JR, Coran AG. Intestinal vaginoplasty for congenital absence of the vagina. J Pediatr Surg. 1992;27(7):885-9.

10. McCraw JB, Massey FM, Shanklin KD, Horton CE. Vaginal reconstruction with gracilis myocutaneous flaps. Plast Reconst Surg.1976;58:176-83.

11. Khazanchi RK, Takkar D. Vaginal depth following reconstruction with pudendal thigh flaps in congenital vaginal atresia. Plast Reconstr Surg. 1997;99(2):592-3.

12. Okada E, Iwahira Y, Maruyama Y. Treatment of vaginal agenesis with an expanded vulval flap. Plast Reconstr Surg. 1996;98(3):530-3.

13. Vesanovi'c S, Panajotovi'c L, Garaleji'c E. Sensibility of vagina reconstructed by McIndoe's method in Mayer- Rokitansky-Küster-Hauser syndrome. Vojnosanit Pregl. 2008;65(6):449-55.

14. Tercan M, Balat O, Bekerecioglu M, Atik B. The use of fibrin glue in the McIndoe's technique of vaginoplasty. Plast Reconstr Surg. 2002;109:706-9. 
15. Hojsguard A, Villadsen I. Mc Indoe's procedure for congenital vaginal agenesis, Complications and results. Br J Plast Surg. 1995;48:97-102.

16. Abbe R. New method of creating a vagina in case of congenital absence. Med Rec (NY). 1898;54:836-8.

17. Frost-Arner L, Aberg M, Jacobsson S. Split skin graft reconstruction in vaginal agenesis: A long-term follow-up. Scand J Plast Reconstr Surg Hand Surg. 2004;38:151.

18. Barnhart KT, Izquierdo A, Pretorius ES, Shera DM, Shabbout M, Shaunik A. Baseline dimensions of the human vagina. Hum Reprod. 2006;21(6):1618-22.

19. Borkowski A, Czaplicki M, Dobronski P. Twenty years of experience with Krzeski's cystovaginoplasty for vaginal agenesis in Mayer-Rokitansky-KüsterHauser syndrome: Anatomical, histological, cytological and functional results. BJU Int. 2008;101:1433-40.

20. Rock JA, Reeves LA, Retto H, Baramki TA, Zacur HA, Jones HW. Success following vaginal creation for Mullerian agenesis. Fertil Steril.1983;39:809-13.

21. Edmonds DK. Congenital malformations of the genital tract and their management. Best Pract Res Clin Obstet Gynecol. 2003;17:19.

Cite this article as: Tharihalli C, Muralikrishna V, Shiva Kumar HC. Surgical management of vaginal agenesis using a modified Mc Indoe's technique: VIMS experience. Int J Reprod Contracept Obstet Gynecol 2017;6:3841-5. 